\title{
Algunas fuentes históricas de la política exterior de Chile.
}

\author{
Pilar Alamos Varas.
}

Este artículo, busca determinar los aspectos de permanencia y cambio en la política exterior de Chile descle una perspectiva histórica, relacionando los periodos de estabilidad con la continuidad y la de los cambios internos con visiones innovadoras. De este modo, se identifican pautas de conducta dirigidas a proyectarlas con una perspectiva histórica y a adaptar los instrumentos de la política exterior a las nuevas circunstancias. De este modo, se destaca que principios como la tradición legalista, la doctrina del equilibrio de poder; la relación ambigua con Estados Unidos y la importancia asignada al Océano Pacifico, son parte constitutiva de la tradición diplomática del país, los que han estado presentes desde los orígenes de la repuiblica.

\section{Introducción}

La política exterior de Chile contiene elementos de permanencia y de cambio que se han manifestado a través de los diversos períodos de su historia. En líneas generales, en los momentos en que ha habido estabilidad han sobresalido los componentes de continuidad; al contrario, cuando se han producido transformaciones tanto internas como externas, han tendido a predominar elementos innovativos.

Es evidente que estos procesos se producen por la interrelación entre diversos factores, ya sea del ámbito interno así como de variables que proceden del sistema internacional.

$\mathrm{Si}$ el objetivo de este proyecto es establecer elementos de continuidad 
y de cambio en la primera mitad de la presente década de los noventa con el fin de apreciar la adecuación de los principales instrumentos de la política exterior para encarar los desafíos a que se ve enfrentado el país, no sólo es fundamental sino también provechoso hacer una revisión histórica acerca del quehacer internacional de Chile.

Como dice Sergio Villalobos, un enfoque histórico de las relaciones internacionales es muy útil para comprender las dimensiones de nuestras actuales vinculaciones. La revisión del pasado de las relaciones internacionales ayuda a iluminar el origen de los problemas, sus vicisitudes y los cambios que han ocurrido. "¿Quién podría desconocer que nuestras relaciones con Perú y los Estados Unidos conforman una larga historia que pesa ineludiblemente hoy día? ¿Cómo desconocer que las políticas económicas internacionales, la influencia de las grandes potencias, las disposiciones aduaneras y hasta los afanes de integración tienen viejas raíces en el pasado?" I

Sin embargo, realizar una enumeración de las acciones de política exterior que el país ha llevado a cabo carece de utilidad; de lo que se trata es de estudiar cómo se ha posicionado Chile a través del tiempo, en este caso el siglo XIX.

De esta manera, en este trabajo interesa determinar que más allá de las acciones internacionales de los diferentes gobiernos existen diversos elementos históricos o fuentes que alimentan la vida internacional del país y que constituyen la base o el sustrato de su política exterior. Se intenta señalar la existencia de ciertos aspectos que han permanecido a través del tiempo y que de alguna manera perduran en la política exterior contemporánea.

Las fuentes de la política exterior chilena podrían definirse "como el conjunto de creencias, valores y tradiciones a través de los cuales el país ha intentado resguardar su soberanía, defender sus intereses nacionales, al mismo tiempo, que se ha esforzado por maximizar en forma solidaria los beneficios provenientes de sus vinculaciones políticas, comerciales, diplomáticas con el medio ambiente regional y mundial. La forma como los gobiernos han creído preservar e incrementar estas tradiciones a través de sus decisiones y actividades ha dado lugar a distintos estilos de conducción

"Sergio Villalobos R., "La situación internacional y la independencia de Chile", en: Walter Sánchez G. y Teresa Pereira L., 150 años de política exterior chilena, (Santiago: Editorial Universitaria, 1977), p. 14. 
político-diplomática de las relaciones internacionales de Chile". ${ }^{2}$

Estos elementos son el reflejo de la vida interna del país y no tienen connotación, es decir no son buenos o malos, positivos o negativos. Subyacen a lo largo de su historia y se acarrean como un equipaje cuyo contenido se ha recibido como herencia después de complejos procesos. De igual modo, son rasgos intermitentes, ya que brotan y desaparecen dependiendo de las circunstancias.

Desenterrar el origen de este legado no sólo es difícil sino que hasta cierto punto infructuoso. Contamos con esta carga -algunas veces está presente en forma inconsciente y no necesariamente es evidente o explícita- y es imposible intentar sacársela de encima.

Se pretende, entonces, identificar las pautas que han guiado la política exterior del país a lo largo del tiempo, lo que ayuda a proyectar su posición internacional con una perspectiva histórica, dando la posibilidad de enfrentar los desafíos de mejor manera y permitiendo adaptar los principales instrumentos.

Para comenzar, se realiza una breve descripción de algunas características propias del país, principalmente a contar de las primeras décadas del siglo pasado -rasgos geográficos, demográficos, etc.- que de cierta forma han influido en su relacionamiento con el exterior. Luego se hace referencia al nacimiento de Chile como nación y a los primeros pasos dados como tal en el plano internacional, destacando que en esta etapa inicial se asentaron algunos de los principales principios que han regido las relaciones internacionales chilenas. Finalmente, partiendo de esta base, se han identificado algunas de las pautas o fuentes históricas de la política exterior nacional: la tradición legalista, la doctrina del equilibrio de poder, la relación ambigua con Estados Unidos y la importancia asignada al Océano Pacífico.

\footnotetext{
" Walter Sánchez, "Las tendencias sobresalientes de la política exterior chilena”, en: Walter Sánchez G. y Teresa Pereira L., op. cit., p. 374. Este autor aprecia cuatro tendencias que a su modo de ver han estado presentes en la trayectoria intemacional de Chile: el americanismo; el nacionalismo político; el legalismo y la búsqueda de un sistema internacional democrático; $y$, el alineamiento y autonomía de Chile en la Guerra Fría y la distensión.
} 


\section{Algunos rasgos constitutivos del país.}

Un primer aspecto a señalar es que existe escasa bibliografía para este período y en general tiene un enfoque historiográfico muchas veces limitado a un relato de la historia diplomática del país. Es difícil estudiar los lineamientos generales de la política exterior de Chile en el siglo XIX debido a la falta de literatura o de obras que vayan más allá de un recuento de las acciones, los conflictos o una enumeración detallada de sucesos.

Sin embargo, revisando algunos autores, se pueden identificar ciertos rasgos propios constitutivos del país que operan como variables internas que conforman una entramada red y que inciden en las políticas exteriores y en su elaboración. ${ }^{3}$

Primeramente, se pueden mencionar algunas características geográficas, como por ejemplo el espacio o territorio. Este determinante factor podría explicar en parte el excesivo centralismo que tradicionalmente ha existido. Por otra parte, los límites naturales del país -desierto, cordillera y mar- le imprimieron un carácter insular, minimizaron las posibilidades de invasiones foráneas y le obligaron a relacionarse con el exterior mirando hacia el mar. A esto último contribuyó también la existencia de buenos puertos a lo largo de la costa, destacándose especialmente Valparaíso muy cercano a la capital. Por otro lado, el gobierno central pudo administrar eficientemente a diferencia de lo que ocurría en otras ciudades como Lima, Bogotá o Buenos Aires. ${ }^{4}$

Con respecto a las características demográficas, a principios del siglo pasado, la población se concentraba en un área fértil y bien comunicada. Hacia 1830, era uno de los países menos poblados de Sudamérica, ya que apenas llegaba al millón de habitantes. Tenía una escasa población indígena, pero bastante primitiva y con un fuerte carácter belicoso. La guerra contra

\footnotetext{
3 Manfred Wilhelmy, "Hacia un análisis de la política exterior chilena contemporánea", ESTUDIOS INTERNACIONALES, №-48, Año XII, octubre-diciembre 1979, pp. 440-471. Aunque este trabajo está referido a la política exterior de Chile de una parte del siglo XX (desde 1946 hasta la segunda mitad de la década de los setenta), se alude a algunos de estos elementos inmutables o de lenta modificación que condicionan su comportamiento internacional. Además de las variables geográficas, demográficas, económicas, etc., dentro de la dimensiōn interna menciona algunos aspectos que si bien están más enfocados a las relaciones internacionales del país en este siglo, son interesantes de destacar, como la cultura política, los grupos de interés y los medios de comunicación, los partidos políticos y el gobierno.

4 Robert Burr, By Reason or Force. Chile and the Balancing of Power in South America, 1830-1905, (Berkeley and Los Angeles: University of California Press, 1967), pp. 14-15.
} 
los araucanos que se prolongó durante varios siglos ayudó a la cohesión de su pueblo, lo que junto a la difícil supervivencia, imprimieron una marca indeleble. A diferencia de otros Estados americanos, la nación surgió con uniformidad étnica y sin conflictos de clase o raciales mayores. Las corrientes inmigratorias, especialmente los vascos, se mezclaron con la aristocracia criolla y fortalecieron los valores preexistentes. ${ }^{5}$ La estructura demográfica que se conformó posteriormente estuvo directamente relacionada con los problemas acarreados por los procesos de urbanización e industrialización. ${ }^{6}$

En cuanto a los recursos naturales, comparado con sus vecinos Perú y Bolivia especialmente, Chile era una región pobre y alejada, donde los metales preciosos eran escasos.

El hecho de ser históricamente una economía basada en la exportación (trigo, plata, salitre, cobre, etc.) y que desde siempre dependiera energéticamente, tuvo implicancias indudables en su estilo de desarrollo. Por otra parte, si bien a fines del siglo pasado hubo una industrialización incipiente, este proceso puede ser considerado atrasado y dependiente. Además, es necesario enfatizar el importante papel que le correspondió jugar al Estado en éste. ${ }^{7}$

Visto desde fuera, la mayoría de los países conocían poco de Chile. "No obstante, el Chile de 1820, pequeño, caótico, pobre, políticamente inestable, con índices altos de criminalidad y asolado por la pobreza, contenía elementos significativos de poder potencial, principalmente aquellos relacionados con la naturaleza de su sociedad, el carácter de su pueblo, y su configuración y localización geográfica".

\section{Los inicios de la política exterior de Chile.}

Aunque resulte obvio afirmarlo, las relaciones exteriores de Chile se iniciaron una vez finalizado el período de emancipación y, por lo tanto, sólo después de la Declaración de Independencia del país se puede hablar

5 Ibid., pp. $13 \cdot 14$.

${ }^{6}$ Manfred Wilhelmy, op. cit., pp. 441-442.

7 lbid., p. 442.

${ }^{8}$ Robert Burr, op. cit., p. 13. 
con propiedad de que se emprendieron acciones en el ámbito externo.

Hay que señalar, en todo caso, que en un primer momento la independencia fue significativa únicamente para las naciones hispanoamericanas que se admitieron entre sí como naciones soberanas inmediatamente. Un poco más tarde, Estados Unidos reconoció formalmente la autonomía. Con respecto a los países europeos, estos demoraron más o menos tiempo según los casos en aceptar el nuevo status del país, pero para ellos Chile "era una personalidad de hecho, que se fue confirmando y fortaleciendo a medida que Chile era reconocido como país independiente". ${ }^{9}$

A partir de 1818, entonces, Chile comenzó a actuar plenamente en el campo internacional, pero estas actuaciones fueron más que nada respuestas a emergencias y desafíos del momento según se presentaban los hechos.

Frente a América, las manifestaciones más importantes estuvieron constituidas por los tratados en los cuales se usaron los sistemas, fórmulas e instituciones del derecho internacional común, para enviar expediciones libertadoras con el fin de ayudar a los otros procesos independentistas. En este primer momento, los países americanos se sentían hermanos producto de que recientemente habían sido parte de un gran núcleo, lo que les hacía difícil tener una vida internacional plena. Esto no quiere decir que llevaron a cabo acciones internacionales comunes, lo que sólo se hizo excepcionalmente debido a la situación inestable por la que estaban pasando. Por esta razón, la política exterior respondía simplemente a objetivos concretos y estaba destinada a satisfacer necesidades circunstanciales. ${ }^{10}$

Por lo tanto, desde esta fecha hubo una serie de acciones internacionales y se usaron las fórmulas, sistemas y principios propios del derecho internacional. Hubo que enfrentar situaciones de emergencia; reclamar el recono-

- Las relaciones con Estados Unidos serán analizadas específicamente más adelante. Con respecto al continente europeo, en la práctica se produjeron relaciones, por ejemplo, a raíz de las indemnizaciones que debian pagarse por pérdidas o comisos de barcos neutrales con motivo de la guerra de independencia previo acuerdos directos a arbitrales. También cabe destacar la misión enviada por O'Higgins a Roma para rendir acatamiento al Papa como soberano espiritual y lograr un entendimiento con la Santa Sede para que el país continuara teniendo el mismo derecho que tenía el rey de presentar al Papa el nombre de algún obispo. Si esto se obtenía, era un reconocimiento del jefe de la iglesia catôlica a la independencia. El resultado fue una fórmula intermedia que consistió en darle al enviado papal, Monseñor Muzi, sólo el título de Vicario Apostólico sin dignidad diplomática propiamente tal. El Papa sólo reconociō la independencia en 1840 . Javier González E., "El aporte de Portales a la formación del Estado nacional como base de una política exterior”, en: Walter Sánchez G. y Teresa Pereira L., op. cit., pp. 33-36. 10 Ibid., pp. 36-37. 
cimiento urgente de la independencia frente a los países europeos; lograr acuerdos sobre indemnizaciones por barcos perdidos, robos, etc. ${ }^{11}$

Durante los primeros años después de la independencia, se vivió en Chile un período de inestabilidad en el cual se sucedieron gobiernos y constituciones que buscaron organizar al país y crear una nueva institucionalidad. Se pensaba con mucho optimismo que un marco legal sería la solución de todos los problemas y, de esta manera, entre 1818 y 1830 se llegaron a promulgar cinco constituciones de diverso corte: moralista, federal, liberal, etc. Todos estos ensayos fracasaron por motivos inevitables como la pobreza imperante, los graves problemas económicos luego de las guerras independentistas y la inexperiencia política. Sin embargo, a diferencia de otros nacientes países, no hubo grandes enfrentamientos y a pesar de que no se resolvió del todo el problema institucional, "numerosos conceptos jurídicos básicos se afianzaron entonces y fueron transmitidos a la posterioridad que los acogió en nuevos códigos". ${ }^{2}$ El logro más importante fue el establecimiento del sistema republicano que era el ideal político al que aspiraba la mayoría de los chilenos.

La situación cambió con el triunfo de José Joaquín Prieto y las fuerzas conservadoras en la batalla de Lircay en abril de 1830. Detrás de Prieto se encontraba el verdadero artífice del nuevo Estado chileno, Diego Portales, de ahí que se hable de este período como la "era portaliana", en la cual se construyó un nuevo orden político, se consolidó la idea de Estado-nación y se impuso una noción de gobierno que echó las bases de la administración legislativa, ejecutiva y judicial del país.

En reacción a la anterior confusión liberal, Portales pretendía terminar con los exóticos conceptos políticos utópicos afirmando que Chile debía darse a sí mismo una estructura política que fuera armónica con su realidad socioeconómica e insistió en que los chilenos debían subordinar sus intereses de clase e individuales a las exigencias de un gobierno ordenado. ${ }^{13}$

\footnotetext{
"Ibid., p. 37.

${ }^{12}$ Sergio Villalobos R., Osvaldo Silva G., Fernando Silva V., Patricio Estellé M., Historia de Chile , (Santiago: Editorial Universitaria, 1974), p. 450.

${ }^{3}$ Primero se tomaron medidas represivas para restablecer el orden en el gobierno: se marginó a los opositores de los puestos influyentes; los militares quedaron bajo el control civil; se censuró ta prensa y se controlaron y restringieron las reuniones políticas. En segundo lugar, se organizó eficientemente la administración pública y se intentó eliminar la corrupción; se sistematizó la estructura financiera del gobierno; se reinstauraron y ampliaron los servicios gubernamentales; se disminuyó el número de empleados públicos. Paralelamente, se implementaron medidas para fomentar la industria, el comercio y la navegación, provocando un crecimiento de la economía que fue ayudado por el descubrimiento de ricas minas de plata en Copiapó. Robert Burr, op. cit., pp. 15-17.
} 
La estructura jurídica se afianzó con la promulgación de la Constitución de 1833 que creó un gobierno central fuerte y con un acentuado presidencialismo.

Sin embargo, la elite gobernante, concentrada en la propia realidad interna, no demostraba interés por la política exterior. No comprendía aún la conexión entre el crecimiento de la riqueza nacional, la estabilidad interna y la necesidad de relacionarse con otras naciones. Una prueba clara de lo anterior era que se consideraba que el Departamento de Asuntos Exteriores no requería un ministro propio y estaba, por lo tanto, bajo la jurisdicción del Ministerio del Interior y de Relaciones Exteriores, lo que así continuó hasta 1871. Además, a esta secretaría se le asignaba un presupuesto que era insuficiente. ${ }^{14}$

Aunque la concentración de Portales también estaba puesta en los temas internos, hay una total coincidencia entre los que han estudiado el período de que también le dedicó una atención especial a la política exterior. Podríamos decir con seguridad que sus orientaciones en materia internacional -como por ejemplo, el rechazo a las aspiraciones expansionistas, el principio de no intervención en los asuntos internos de otros países, la vocación marítima, la igualdad jurídica de todas las naciones en el sistema internacional, la importancia de la integración económica de los países americanos, entre otras-, indudablemente sentaron las bases de la tradición diplomática chilena. Con esto no se pretende afirmar que los individuos por sí solos son capaces de concebir conceptos nuevos o producir cambios institucionales claves, sino que Portales supo encauzar una cierta intuición del orden general que tanto la clase dirigente como la nación querían para sí mismas. La sociedad en general se sintió identificada con su ideario y prueba de ello es que su inesperada muerte no afectó la obra que estaba recién comenzando. ${ }^{15}$

Si bien en esta época existía un escaso grupo de hombres educados con interés y experiencia en los asuntos internacionales, Portales encontró en la figura polifacética y sobresaliente de Andrés Bello un complemento fundamental para implementar estos principios y se puede decir que a ambos se debe el nacimiento de la política internacional de Chile. 
Se considera a Bello el creador jurídico de la orientación internacional chilena. Su obra como internacionalista -plasmada en las tres décadas en que participó activamente en la formulación de la política exterior imprimiéndole una continuidad lógica a las relaciones internacionales del país y a través de múltiples publicaciones ${ }^{16}$ tuvo como objetivo proveer a las nacientes y débiles naciones de un conocimiento legal para defenderse por sí mismas de las potencias más antiguas y poderosas, sosteniendo la existencia de un sistema internacional en el cual el derecho de las naciones derivara de la ley y no del poder. ${ }^{17}$ En todo caso, hay que recalcar que este notable hombre público ejerció una enorme influencia no sólo en Chile y que su importancia puede reconocerse en los conceptos sudamericanos sobre relaciones internacionales a través de todo el continente.

No obstante, Andrés Bello tampoco intentó modificar la percepción aislacionista del grupo dirigente, la que se veía reforzada por las características geográficas anteriormente mencionadas y por una estructura de poder internacional que era momentáneamente propicia a Chile. Hasta 1836, ni las grandes potencias europeas, ni Estados Unidos, ni otros Estados sudamericanos constituyeron una amenaza para el país. Esto permitió al nuevo gobierno chileno demorar la formulación de una acabada política exterior y concentrarse en el desarrollo doméstico. ${ }^{18}$

Los tres fundamentos en que se basó la política exterior chilena en ese período fueron la necesidad de prevenir la intervención foránea en los asuntos internos, eludir los conflictos vecinales y promover relaciones comerciales con el mundo.

De acuerdo con esto, ante las grandes potencias que no reconocían a Chile como un igual, se decidió prevenir rivalidades para impedir posibles intromisiones y se procuró implementar los vínculos económicos. Con respecto a los países del continente, se pudo funcionar sobre la base de una relativa igualdad y promover sus intereses con mayor fuerza, manteniendo relaciones relevantes sólo con sus vecinos Perú, Bolivia y las Pro-

\footnotetext{
${ }^{16}$ Su legado consistió en una intensa investigaciôn del Derecho Internacional Público, que se tradujo en un interesante volumen y en diversos informes que conforman la jurisprudencia de la Cancillería chilena en materia internacional, y en diversas creaciones jurídicas como la inmutabilióad de los tratados y la clăusula de la "nación más favorecida". Ibid., pp. 112-113.

17 Robert Burr, op. cit., pp. 18·19.

${ }^{13}$ lbid., pp. 19-22.
} 
vincias Unidas del Río de la Plata. ${ }^{19}$ Dos ejemplos fueron la participación de Chile como mediador en la anarquía que se vivía en Argentina en 1830 y al año siguiente en el complejo panorama entre Perú y Bolivia. Ambas intervenciones dejaron descontento a Chile y le impulsaron a distanciarse cada vez más de los conflictos internos hispanoamericanos. ${ }^{20}$

Cuando en 1836 la estructura de poder dejó de ser favorable para Chile, la situación cambió. Las aspiraciones comerciales y la estabilidad interna del país se vieron seriamente amenazadas por la Confederación Perú-Boliviana. ${ }^{21}$ Este peligro fue visualizado claramente por Diego Portales, quien temía que la intención de Santa Cruz de reconstruir el antiguo imperio incaico se extendiera también a Chile, Ecuador y el norte de Argentina, provocando un quiebre del equilibrio entre países relativamente semejantes y equivalentes. ${ }^{22}$

En su opinión era nocivo que existiera un país muy superior a los otros en territorio, población, riqueza, fuerzas armadas, etc. Sin embargo, más que la posibilidad de una derrota en un encuentro armado, le asustaba la posibilidad de que se produjera internamente una conmoción generalizada que provocaría que Santa Cruz se apropiara finalmente del país y que se le eliminara como potencia naval en el Pacífico. Por lo tanto, la creación de un solo Estado formado por Perú y Bolivia era un claro caso de ruptura del orden establecido que había que frenar oportunamente. ${ }^{23}$

\footnotetext{
19 lbid., pp. 21-22.

${ }^{20} \mathrm{El}$ arbitraje en la "guerra federal" del país trasandino fracasô debido al rechazo de la mayoría de sus provincias. Pero mayor trascendencia tuvo la mediaciôn entre los vecinos del norte. Aunque se logró un acuerdo, se temía que ambos países sölo pretendieran dillatar una situación en beneficio de ellos mismos, lo que más tarde se vio confirmado. Mario Barros van Buren, op. cit., pp. 117-118.

${ }^{21}$ En 1835, Diego Portales, había pronosticado que las diferencias entre Chile y Perú en materia de aranceles podian llevar a un enfrentamiento armado. Posteriormente, el afán expansionista del mariscal Andrês de Santa Cruz y la creación de la Confederaciôn Perú-Boliviana le indicaron que la posibilidad de un conflicto era inevitable. El gobierno de Prieto, reelegido por otros cinco años, demostrô su preocupación a travês de una serie de iniciativas para terminar con la Confederación, siendo Portales el más decidido impulsor de la guerra. La fuerte oposición que concitaba el régimen culminó con el asesinato del Ministro en junio de 1837 , lo que produjo un tremendo impacto y originó una actitud espiritual nunca antes vista; incluso se pensó que en el hecho pudieran haber intereses foráneos y que volvería la inestabilidad y el caos. La impopularidad que causaba la posibilidad de una guerra contra ta Confederación se revirtió y se decidió terminar con la obra de Santa Cruz. En noviembre de ese año se firmó un tratado entre el mariscal y el jefe del ejército expedicionario chileno, que luego fue rechazado por el gobierno. En julio de ${ }^{1838}$, zarparon las tropas hacia Perú y luego de diversos encuentros, las fuerzas peruanas fueron derrotadas en Yungay en enero de 1839. Sergio Villalobos et al, op. cit., pp. 534-536.

22 Para combatir contra la Confederaciôn, Portales trató de buscar aliados en el exterior, logrando concertarse con Argentina. Igualmente, pretendió que Ecuador se involucrara en el conflicto, pero sin éxito. En Europa, no consiguiố el apoyo de Francia y Gran Bretaña. Lo mismo ocurrió con Estados Unidos y los otros paises americanos. Mario Barros van Buren, op. cit., pp. 129-132.

${ }^{23}$ lbid., pp. 126-129.
} 
Este conflicto, en un principio atribuible sólo a Portales pero que posteriormente fue anhelado y respaldado por todos los chilenos, contribuyó a la afirmación de la identidad nacional y constituyó el primer y más importante ejemplo de una política internacional que obedecía a objetivos profundos y no sólo a la reacción frente a sucesos coyunturales. "La guerra, por lo tanto, fue una acción derivada de un país que ya tiene su personalidad propia, y que quiere oponerse a cualquiera que la deshaga o rompa. La personalidad nacional chilena se ha desarrollado, y se lucha contra quienes atentan contra ella. La guerra se hace porque Chile es una Nación que ya tiene claro el concepto de sí misma, Santa Cruz era un riesgo y un peligro, y por eso y no por otras razones debía desaparecer. Porque tal fue el sentido de la empresa, se puede comprender que si al principio la guerra no fue claramente popular, la popularidad de la guerra vino después, una guerra de motivos subalternos no habría sobrevivido a Portales". ${ }^{24}$

Durante este enfrentamiento, evolucionaron los conceptos en cuanto al rol internacional de Chile. La política exterior chilena basada en el aislacionismo, no intervención y "alianzas no enredosas" cambió debido a la necesidad de restaurar el equilibrio de poder que había sido quebrantado. El conflicto hizo pensar a los chilenos que el logro de sus objetivos internos estaba amenazando su futuro económico y hacía peligrar el progreso social del país. ${ }^{25}$ De esta forma, para continuar su avance como Estado-nación, era absolutamente imprescindible restablecer la estructura existente antes de la Confederación. Después de la victoria de Yungay, la idea de que la seguridad nacional dependía del mantenimiento del equilibrio de poder llevó a que éste se convirtiera en una doctrina para el país como veremos más adelante. ${ }^{26}$

\footnotetext{
${ }^{24}$ Javier González E., op. cit., p. 43.

${ }^{25}$ En todo caso, los objetivos sólo fueron evitar el riesgo para Chile y prevenir el rompimiento del equilibrio americano, ya que un vez finalizado el conflicto y luego del triunfo, al país sólo le interesó la disolución de la Confederación y no se pretendió, por ejemplo, intervenir en las elecciones presidenciales de Perü para imponer una persona determinada o pedir compensaciones territoriales, lo que se adecuaba plenamente a los postulados portalianos mencionados anteriormente. Ibid., p. 43.

${ }^{26}$ Robert Burr, op. cit., p. 57.
} 


\section{La tradición legalista}

Que Chile es un país donde históricamente ha existido un gran apego a la ley es una afirmación que nadie pone en duda. Esta tradición legalista constituye una de las fuentes de la política exterior nacional que está presente no sólo desde sus inicios como país independiente, sino que su origen se remonta a la época colonial.

El legalismo es una de las bases de la herencia cultural de Chile y sirve de contexto o marco al pensamiento y a la acción política del país. La política exterior chilena, cuya primera referencia es la ley, es producto de una cultura que está condicionada por una base legal. ${ }^{27}$

El énfasis en la ley fue un rasgo dominante del Chile colonial. La implantación del legalismo y su consecuente estructura jerárquica fue posible gracias a algunos factores. Por un lado, Chile fue colonizado durante el reinado de Felipe II, un monarca absoluto quien estableció una administración jerarquizada que sobrevivió tres siglos. Tanto en la madre patria como en las posesiones de ultramar la norma ordenó las relaciones entre los individuos. Por el otro, esta jerarquía con el rey en la cima, fue apoyada por una iglesia igualmente muy poderosa. De esta forma, durante el período colonial, Chile vivió en un contexto legalista y de orden jerárquico, moldeado por las enseñanzas medievales de la iglesia y la estructura colonial impuesta por un monarca absoluto. ${ }^{28}$

A principios del siglo XIX, cuando Napoleón logró someter a la monarquía española, la estructura colonial recibió un fuerte golpe y la cúspide de la jerarquía social fue removida. El país, que estaba condicionado a obedecer al rey quien derivaba su autoridad de Dios, debía ahora rendir lealtad a un monarca establecido por un gobierno revolucionario cuyo poder ahora emanaba de la razón. ${ }^{29}$

\footnotetext{
${ }^{27}$ Lawrence Littwin plantea que el legalismo es el patrón principal de la política exterior de Chile. En su libro explica el origen de este fenómeno y distingue tres etapas que a su juicio se han dado histơricamente. También analiza los factores que influyen en la formulación de la política exterior chilena y se refiere a un caso de estudio que comprueba su hipốtesis: la decisión de romper relaciones con Cuba en 1964. Para efectos de nuestra investigación nos han interesado sobre todo las ideas contenidas en el primer capítulo. Véase Lawrence Littwin, An integrated view of Chilean Foreign Policy, (Ann Arbor, Michigan: University Microfilms, Inc., 1987), pp. 1-37, 198-200.

${ }^{28}$ Ibid., pp.16-17, 24 .

29 Ibid., p. 24.
} 
Finalmente, Chile optó por romper los lazos políticos que lo ataban con la metrópolis y buscar la mejor forma para autogobernarse. De acuerdo a lo que señalamos anteriormente, la clase política tenía la idea de que un marco legal permitiría organizar y dar estabilidad a la joven nación. Pero estos intentos no tuvieron éxito debido a las motivos previamente mencionados y porque los caudillos que se sucedieron en el poder fracasaron por el hecho de que su autoridad estaba basada en su personalidad y en su fuerza en lugar de la ley. Como dice Littwin, "el desorden duró hasta que fueron redescubiertos los ingredientes de la estabilidad y el sistema político fue reestructurado según los dictados de la receta de la legalidad"30, constituyendo una excepción entre las ex-colonias hispanoamericanas.

Luego del período de inestabilidad, era necesario ver qué es lo que antes había producido orden, paz y progreso en Chile. Como ya vimos, fue Diego Portales quien supo darse cuenta de lo que el país realmente requería y encontró la fórmula apropiada: la corona, que permitía la estabilidad política, y la iglesia, ya que no se concebía una acción política sin estar inspirada directamente en lo moral. ${ }^{31}$ Portales aprovechó estos dos elementos y consiguió restaurar la autoridad dentro de un marco legal, la Constitución de 1833, que devolvió al país a la tradición monárquica y aristocrática del período precedente.

No olvidemos que para llevar a cabo sus planes Portales no estuvo solo, sino que contó con la valiosa ayuda de Andrés Bello. "El aporte de Bello durante sus 30 años en la cancillería marcó una tendencia al legalismo, al apego a soluciones pacíficas de las controversias y al respeto irrestricto de Chile por la palabra empeñada". ${ }^{32}$ El fue quien diseñó los principios jurídicos que debían salvaguardar la igualdad entre las naciones y el principio de no intervención que son los elementos más importantes para la construcción de un sistema internacional democrático.

Este respeto al derecho internacional por sobre otra consideración de fuerza o poder es lo que Walter Sánchez llama "legalismo", que "es la fe casi utópica en la fuerza de la Ley y el Derecho, como fuente de ciudadanos y naciones virtuosas y solidarias". ${ }^{33}$ Esta actitud jurídica ha sido sostenida

\footnotetext{
30 Ibid., p. 25.

${ }^{31}$ Javier González E., op. cit., p. 39.

32 Walter Sánchez, op. cit., p. 388.

33 lbid., p. 387.
} 
por Chile a través de toda su actividad internacional y, en su opinión, cuando Chile recurrió a la fuerza lo hizo sólo como una última respuesta frente a situaciones que hacían peligrar el equilibrio regional al romperse las condiciones en las que el derecho internacional podía actuar regulando los conflictos. ${ }^{34}$

La permanente referencia al derecho internacional y la adhesión a sus dictados constituye un reflejo de más de cuatrocientos años de condicionamiento legalista. Se puede afirmar también que este legalismo ha sido funcional a la política exterior chilena ya que está mezclado con el concepto de neutralidad explicada en función de la dependencia económica, la necesidad de comercio, la vulnerabilidad geográfica, la hostilidad con Estados Unidos y el sentimiento proclive hacia Europa. ${ }^{35}$

\section{La busqueda del equilibrio de poder}

Desde la década de 1830 hasta fines del siglo XIX la política internacional de Chile estuvo marcada por la búsqueda y el mantenimiento del equilibrio de poder, constituyendo, por lo tanto, una de las constantes de su política exterior. La lucha permanente por conseguir que no se produjera un desbalance entre las fuerzas llegó a constituir una verdadera doctrina para los chilenos.

Durante este período, la elite dirigente procuró mantener una estructura de poder favorable cuando algún cambio externo pusiera en peligro sus intereses vitales. De esta forma, compitió con otros para lograr superioridad comercial; para controlar recursos como el guano, salitre o plata; para retener territorios con potencial agrícola o estratégico; y para la superioridad naval o militar. Con el fin de lograr estos propósitos, Chile estuvo dispuesto a utilizar todos los medios -desde los diplomáticos hasta incluso la fuerzalo que le permitió asegurar su hegemonía en la costa del Pacífico. ${ }^{36}$

\footnotetext{
${ }^{34}$ Las guerras a las que Chile se vio enfrentado en el siglo pasado aparecen analizadas en otras secciones de este trabajo. Por otra parte, su apego al derecho internacional le habría dado prestigio entre los demás países, lo que se ejemplifica en que actuara como mediador en diversas oportunidades. lbid., pp. 387-388.

${ }^{35}$ L.awrence Littwin, op. cit., pp. 37 y 200.
} 
Esta política de equilibrio de poder no estuvo exenta de contenido legal. Los principios aportados por Andrés Bello permitieron que la política exterior se enmarcara en la idea de que un ordenamiento jurídico internacional era compatible y se apoyaba en este equilibrio. ${ }^{37}$

Antes de la Guerra contra la Confederación Perú-Boliviana en 1836, Chile se desenvolvía dentro una estructura de poder propicia en Sudamérica. Se pensaba que las naciones sudamericanas eran parte de un sistema cerrado de potencias políticas cuyo interés común era mantener un equilibrio entre ellas mismas. Debido a la anarquía en que vivían estos países y partiendo de la base de que la estabilidad se regulaba por sí misma automáticamente, Chile pudo llevar a cabo una política de aislacionismo, de no interferencia, o de rechazo a la formación de bloques y alianzas.

Sin embargo, la unificación de los vecinos del norte dejó en claro las deficiencias del mecanismo y la nación vio amenazados los logros políticos, económicos y sociales que tan duramente se habían conseguido. Para continuar avanzando por el camino trazado debía restaurarse el equilibrio que se había roto, aunque fuera empleando la fuerza.

Como dice Emilio Meneses "la elite gobernante percibía que la independencia nacional podía estar asegurada sólo luchando -con medios diplomáticos o militares- contra cualquier potencia o coalición que amenazaba con dominar el subcontinente". ${ }^{38}$ En ese momento, Diego Portales era quien percibía con mayor clarividencia el desbalance de las fuerzas en el continente. Según vimos, se percató tempranamente del peligro que significaba la Confederación, de ahí que opinaba que ésta debía desaparecer de la

\footnotetext{
${ }^{36}$ En su libro By Reason or Force, Robert Burr plantea que Chile fue una de las naciones sudamericanas que afectó y fue afectada por el desarrollo de un sistema continental de potencias políticas en Sudamérica. La simboolica frase "Por la razón o la fuerza" que se grabó en su escudo nacional en 1834, refleja en su opinión que este paîs "iba a surgir desde la obscuridad y llegar a ser una fuerza importante en el continente". Sitúa su estudio entre 1830 y 1905 , comenzando por describir la manera en que Chile fue forjando la estabilidad interna que le sirvió como un prerequisito para alcanzar una posiciôn de poder. Lo finaliza cuando el país logró acuerdos con Argentina para un equilibrio continental dándole la hegemonía en la Costa del Pacífico e intercambió con Bolivia ratificaciones de un tratado simbolizando esta preponderancia. Ver Robert Burr, op. cit., pp. 260-262. Gran parte de lo que se examina en esta sección está basada en esta obra y en otras que también hacen referencia a este autor. Hay que destacar, en todo caso, que no se hace un recuento histórico, por lo que se omiten muchos hechos importantes. Se trata más bien de señalar cômo Chile fue adaptándose para posicionarse internacionalmente.

${ }^{37}$ Emilio Meneses C., "Coping with Decline: Chilean Foreign Policy during the Twentieth Century, 19021972". Tesis de Doctorado, Balliol College, Universidad de Oxford, 1987, pp. 12-13.

${ }^{38}$ Jbid., p. 9.
} 
escena americana y que él fuera el más tenaz partidario de declarar la guerra, a pesar de la oposición que ésta despertaba.

Luego de obtenido el triunfo en el conflicto, Chile se conformó con ver restaurado el equilibrio, evitó intervenir en la política interna peruana y no reclamó compensaciones territoriales. Pero los principios que sustentaban la política exterior chilena evolucionaron y se dejó de depender de un mecanismo auto regulado, implementándose una política efectiva para intentar mantener una estructura favorable a su supremacía. "Por un breve momento después de la guerra este objetivo fue buscado a través de la negociación de pactos de seguridad bilaterales y la promoción de un congreso americano. Cuando esos esfuerzos fracasaron, Chile asumió el rol de regulador del equilibrio de poder en el área de sus intereses vitales inmediatos". ${ }^{39}$

El país sabía que no podía jugar un rol preponderante con respecto a las potencias extracontinentales. Sudamérica era el sistema en el cual se sentía parte y sólo dentro de éste esperaba ser una influencia importante. Así, la política chilena hacia las grandes potencias estuvo subordinada a sus asuntos sudamericanos. No obstante, dado que esas naciones podían llegar a influir decisivamente en el subcontinente, Chile llevó a cabo acciones acomodaticias para mantenerlas a raya basándose en el hecho de que las frecuentes pugnas entre ellas le permitiría frenarlas. Simultáneamente, impulsó el intercambio comercial e importó tecnología de Estados Unidos y Europa que le ayudaron a competir mejor con los países de su entorno, pero evitando que interfirieran. ${ }^{40}$

Chile enfrentó abiertamente a una gran potencia sólo cuando le pareció que estaban en riesgo sus propios intereses y la estructura de poder sudamericana, por ejemplo, cuando España respaldô la expedición del general Juan José Flores ${ }^{41}$; cuando Estados Unidos propuso un protectorado sobre

\footnotetext{
39 Robert Burr, op. cit., p. 261.

$4^{00}$ Ibid., pp. 260-261.

${ }^{42}$ Este, quien fue el primer presidente de Ecuador y había dimitido luego de una revolución, organizó desde Europa una expedición a América en 1846 con el fin de formar un solo país con Colombia, Ecuador y Perú. Si bien el intento fracasó ya que España le quitó el apoyo dado en un principio, su importancia radica en que originó el Congreso de Lima de 1847. Chile participó en éste y se firmó un Tratado en el cual los países se comprometían a defenderse entre sí, a no atacarse mutuamente y a no intervenir en los asuntos internos. Pero ninguno de los países signatarios lo ratíficó posteriormente. Marjo Barros van Buren, op. cit., pp. 168-171.
} 
Ecuador; cuando España capturó las islas Chincha en $1864^{42}$; cuando Estados Unidos intervino en la Guerra del Pacífico; o cuando el poderío naval inglés y su control sobre la industria salitrera amenazaron potencialmente a la fuente de riqueza que era el sustento de la superioridad chilena en la región. ${ }^{43}$

Como regulador del equilibrio de poder, Chile estuvo dispuesto a emplear la fuerza sólo para mantener el status quo territorial en Perú y Bolivia. Pero posteriormente, al aumentar su fuerza y su comercio en el Pacífico y dado que el poderío peruano también creció, Chile pasó a controlar el equilibrio y logró la hegemonía en toda la costa de este océano.

Chile pudo mantener una estructura favorable mientras cultivó relaciones amistosas con Ecuador y Colombia y existió una relativa superioridad chilena sobre Perú. Pero, a principios de 1860, el sistema comenzó a cambiar debido a la progresiva integración de Sudamérica a la economía mundial y al surgimiento de Argentina como la cuarta gran potencia regional. Por su parte, Perú intentó formar una alianza anti chilena tripartita con este último y Bolivia. Para responder a las transformaciones que se estaban produciendo, Chile buscó un permanente entendimiento con Brasil que le sirviera de contrapeso a su vecino transandino. ${ }^{44}$

La guerra contra España en 1865 también contribuyó a desestabilizar el ordenamiento, ya que además de los grandes daños económicos producto de la destrucción de Valparaíso y de la flota mercante, quedó en evidencia que la nación no estaba preparada para un conflicto de este tipo. Por otro lado, Perú aumentó su poder en el océano y comenzó a acercarse a Bolivia dada la situación desventajosa en que quedó Chile. Ahora, éste debía renovar su política internacional buscando un sistema de alianzas pragmáticas que condujera a un equilibrio de poderes para enfrentar las agresiones extracontinentales y neutralizar los conflictos americanos. ${ }^{45}$

Según Robert Burr, desde el punto de vista chileno, la diplomacia sudamericana mostraba el advenimiento de un nuevo período en las relaciones

42 juicio de Mario Barros, la ocupación de estas islas impactó fuertemente en Chile. La desmesurada reacción contra España, un americanismo exacerbado y una solidaridad mal entendida con Perú, provocaron que se viera envuelto en un conflicto que no merecía tanta importancia. Ibid., pp. 237-240.

${ }^{43}$ Robert Burr, op. cit., pp. 260-261.

44 Ibid., p. 262.

45 Mario Barros van Buren, op. cit., pp. 251-255. 
entre los países del continente. Habían aparecido cuatro potencias -Argentina, Brasil, Perú y Bolivia- que se integraban exitosamente a la economía mundial y que tenían objetivos comunes que las entrelazaban fuertemente. "Como resultado de este cambio en la estructura internacional de Sudamérica, el manejo del sistema de la costa del Pacífico resultó insuficiente para preservar la libertad de acción de Chile y hacer progresar sus intereses vitales." 46

El salitre localizado en las regiones nortinas creó una situación peligrosa al poner en pugna a los países que querían beneficiarse con su explotación. Así, en 1873, el equilibrio sudamericano se vio amenazado nuevamente cuando Perú y Bolivia firmaron un pacto secreto defensivo. Ignorante de este hecho, al año siguiente, Chile logró un acuerdo con Bolivia mediante el cual se establecía que no se subirían los impuestos a los capitales chilenos situados al norte del paralelo 24 .

El no cumplimiento de lo acordado por parte de Bolivia provocó que Chile declarara la guerra a estos dos países. Aunque no nos detendremos en los pormenores, se puede afirmar que la Guerra del Pacífico entre 1879 y 1883 fue el conflicto internacional más importante en el que Chile ha participado. ${ }^{47}$

Luego de la ocupación de Lima y Callao y la destrucción del ejército peruano en la sierra, Chile obtuvo el triunfo. Con Perú, el tratado de Ancón de 1883, resolvió que se cedía a perpetuidad e incondicionalmente el territorio de la provincia de Tarapacá y temporalmente Tacna y Arica, hasta que un posterior plebiscito definiera su soberanía. Con Bolivia, en 1884 y mediante un tratado de tregua, se estipuló que Chile mantendría la ocupación de Antofagasta ejerciendo plena soberanía, lo que permitió restablecer las relaciones comerciales entre ambos países. Chile pudo, entonces, controlar las riquezas salitreras y emergió como el país sudamericano más rico y poderoso de la costa occidental, alterando por completo el equilibrio de poder.

El período posterior a este enfrentamiento fue visto como una era dorada para el poder internacional de Chile pero, como lo expresa Emilio Meneses, la época del salitre hizo que Chile olvidara que era todavía una nación

${ }^{46}$ Robert Burr, op. cit., pp. 136-137.

47 Emilio Meneses C., op.cit., pp. 13-14. 
inmadura lo que trajo posteriores problemas con los que habían sido derrotados, según veremos más adelante. ${ }^{48}$

Controlar una situación favorable a sus intereses y al mismo tiempo de gran fragilidad era difícil para Chile. De esta manera, algunos eventos ocurridos a principios de 1890 hicieron peligrar su posición internacional.

Por una parte, los problemas políticos internos eran cada vez más difíciles de solucionar. La pugna entre los que estaban por mantener un sistema presidencialista fuerte y los que apoyaban un sistema en el que el Congreso tuviera mayor influencia, hizo que en 1891 se desatara una guerra civil. Paralelamente, la rivalidad con Estados Unidos se manifestó a través del caso del Baltimore, un delicado asunto diplomático que casi los llevó a las armas. ${ }^{49}$

En un año, Chile sufrió una devastadora guerra interna, una nueva forma de gobierno parlamentario y estuvo muy cerca de un conflicto armado con una gran potencia. A pesar de que su poder económico se había acrecentado -debido a que sus ingresos casi se habían cuadruplicado y sus fuerzas armadas gozaban de gran prestigio y respeto- el país se encontraba aislado en Sudamérica. Esta situación no le permitió resolver sus problemas fronterizos ni conseguir apoyo internacional. ${ }^{50}$

De acuerdo a Mario Barros, después del asunto del Baltimore, Chile basó su política exterior sobre cuatro pilares: desconfianza en cualquier organismo internacional en que participara Washington o alguno de sus aliados, el imperativo de tener amigos poderosos en Europa, la conciencia de que en caso de un conflicto internacional Chile debía contar sólo con sus propias fuerzas y la necesidad de tener una marina de guerra capaz de asegurar su supervivencia. ${ }^{51}$

Con respecto a lo primero, por ejemplo, Chile pidió garantía a Estados Unidos de que ninguna moción contraria a sus intereses formaría parte de las agendas de los Congresos Panamericanos de 1901 y 1906. Por otra parte, temía la presencia norteamericana en el Pacífico sur -región de la

\footnotetext{
${ }^{4}$ B lbid., p. 14 .

${ }_{49}$ Sobre este asunto nos referiremos en la sección sobre las relaciones con Estados Unidos.

so Ibid., pp. 16-18.

51 Mario Barros van Buren, op. cit., pp. 554-555. Aunque Emilio Meneses está de acuerdo con dicha hipótesis, sostiene que esos pilares se mantuvieron hasta los Pactos de Mayo de 1902 y no hasta 1943 como afirma Barros.
} 
cual Chile creía ser su defensor natural- y una intervención en favor de Perú en la controversia de Tacna y Arica todavía pendiente. Con referencia a lo segundo, se acercó fundamentalmente a Gran Bretaña y Alemania para equilibrar las ambiciones de las grandes potencias y contener el crecimiento de la influencia norteamericana en el hemisferio. En lo tercero, Chile rechazó cualquier alianza y prefirió mantenerse solo, enfrentando una eventual crisis con sus propios medios. Por último, sentía que el poderío naval había sido un importante instrumento para su seguridad. ${ }^{52}$

A partir de 1891, entonces, Chile se vio forzado a efectuar cambios en su tradicional política de equilibrio de poder ya que su posición internacional comenzó a deteriorarse debido a diversos factores: la inestabilidad política interna, las dificultades económicas, el progresivo desarrollo de Argentina, los problemas vecinales y la falta de apoyo de otras naciones. ${ }^{53}$

En primer lugar, el nuevo régimen parlamentario amenazó la estabilidad política interna ya que la eficacia del gobierno, y por consiguiente también de la política exterior, se vio perjudicada por los sucesivos cambios de gabinete. El nuevo sistema político funcionaba mal y nada se hizo para mejorarlo. El estilo que se instauró y cuya manifestación más clara fue la rotativa ministerial -que en algunos momentos llevó a que en un período presidencial hubieran 10 ministros encargados de la Oficina de Relaciones Exteriores- constituyó un freno a la evolución institucional.

Económicamente, el país empezó a experimentar problemas: a pesar que siguió creciendo, dependía cada vez más de las exportaciones de salitre; la base de los ingresos nacionales disminuyó ya que lo recaudado vía impuestos se redujo al mínimo; se suprimieron todos los derechos de aduana a las exportaciones (con excepción del salitre y el yodo); las importaciones como porcentaje de los ingresos totales decrecieron. A juicio de Burr y Meneses, los gobiernos no supieron aprovechar las enormes ganancias que entraron por el salitre y en lugar de invertir en fuentes de crecimiento permanente éstas se gastaron irresponsablemente, afectando la gravitación de Chile en los asuntos sudamericanos. ${ }^{54}$

\footnotetext{
\$2 Emilio Meneses C., op.cit., pp. 19-22.

33 Emilio Meneses realiza un excelente análisis de cómo Chile empezó a declinar su poder en la década de 1890 en el cual se basa esta parte del trabajo. Ibid., pp. 24-30.

${ }^{54}$ Ambos autores hablan de una decadencia moral de la aristocracia chilena, la cual perdió el espíritu emprendedor, la vitalidad y la moderación característicos del perî́odo colonial. bid., pp. 24-26 y Robert Burr, op. cit., p. 198.
} 
Otro factor que contribuyó al desgaste internacional chileno fue el surgimiento de Argentina como una nación más poderosa. Comparativamente, crecía más rápidamente que Chile. Su población, por ejemplo, debido a la inmigración europea, de ser prácticamente igual en 1880 casi duplicó a la chilena veinte años más tarde. Esto repercutió en el ámbito económico, ya que mientras Chile aumentaba considerablemente sus ingresos gracias a un solo recurso, el salitre, Argentina dependía de los impuestos provenientes de sus habitantes, su capital y trabajo, doblando los ingresos chilenos. El aumento del poder argentino no sólo era percibido por ambos países, sino también por los extranjeros como Gran Bretaña o Perú.

Por otro lado, los vecinos inmediatos de Chile comenzaron a bloquear su creciente poder y su temido expansionismo territorial, mediante una diplomacia concertada de cercamiento. Los problemas limítrofes estaban latentes: mientras Bolivia presionaba por una salida al mar, Perú pretendía recuperar Tacna y Arica; con Argentina no estaban definidos los límites de la Patagonia Central y de la Puna de Atacama.

A lo anterior se agregaba que Chile ya no contaba con Brasil como un posible aliado y el resto de Sudamérica le mostraba resentimiento y desconfianza. La relaciones con Estados Unidos tampoco eran buenas, ya que se percibía que éste estaba resuelto a frenar su expansionismo, ya sea apoyando a Perú y Bolivia o usando a Argentina como contrapeso. Mientras tanto, Chile se negaba a perder su poder como potencia regional y trató por todos los medios de llegar a acuerdos separados con sus vecinos.

Finalmente, Argentina y Chile llegaron a un acuerdo en 1902 por medio de los Pactos de Mayo, que contemplaron tres puntos principales: la limitación de armamento, la no intervención de Argentina en el Pacífico y el arbitraje obligatorio para dirimir todas las controversias entre ambos. Como consecuencia de ellos, se logró un entendimiento dividiendo áreas de hegemonía en Sudamérica: mientras Chile se concentraría en el Pacífico y se comprometía a poner fin a su expansionismo, Argentina se obligaba a no interferir en los asuntos del Pacífico y se le reconocería su preeminencia en el Atlántico y el Río de la Plata.

En 1904 se firmó un tratado de paz con Bolivia, que consagró el dominio absoluto y perpetuo de Chile en los territorios ocupados por el pacto de tregua. Con Perú se llegó a un acuerdo años más tarde, en 1929, mediante el cual éste quedó en posesión de Tacna y Chile de Arica. 
Esta política de acomodación con los vecinos que permitió llegar a los acuerdos con Argentina y Bolivia, creó una situación muy conveniente para ellos y que querían conservar. Los nuevos compromisos legales contraídos en los acuerdos vecinales, la pérdida de su poder económico y consecuentemente de la fuerza militar, tuvieron como resultado que la política de equilibrio que Chile sostuvo por tantas décadas careciera de sentido.

Meneses concluye, entonces, que todos estos hechos influyeron en el término de la vigencia de los cuatro fundamentos sobre los cuales Chile basaba su política exterior desde la década de 1890: la pugna con Estados Unidos y la amistad con Alemania dejaron de importar después de la Primera Guerra Mundial, ya no se requería una armada poderosa porque Chile trató de evitar a toda costa conflictos armados y, por lo mismo, la dependencia de sus propios medios ya no tuvo relevancia. ${ }^{55}$

\section{La relación ambigua con Estados Unidos}

La relación entre Estados Unidos y Chile ha estado marcada históricamente por momentos de convergencia y de distanciamiento, no en vano algunos autores la han definido como una "amistad esquiva". ${ }^{56}$ Esta particular forma de relacionamiento ha estado presente a través de las diferentes etapas de la política exterior chilena llegando a constituir una de sus fuentes.

En líneas generales, se puede decir que los períodos de plena coincidencia entre ambos países han sido más bien excepcionales, sobresaliendo los momentos de tensión más que los acuerdos.

Durante el siglo XIX y principios del XX tanto uno como otro se encontraban en proceso de formación y disputaban su influencia en el ámbito sudamericano, por lo que predominó más el conflicto que la cooperación. Posteriormente, en la segunda mitad del siglo XX, el ámbito interestatal

\footnotetext{
55 Emilio Meneses C., op.cit., pp. 54-55.

${ }^{56}$ Heraldo Muñoz y Carlos Portales, Una amistad esquiva. Las relaciones de Estados Unidos y Chile, (Santiago: Pehuén, 1987). En este libro se examinan especialmente las relaciones entre ambos países bajo el régimen militar de 1973 y se sostiene que las vinculaciones han sido contradictorias históricamente. El primer capítulo se refiere a los antecedentes históricos, analizando las primeras tensiones ocurridas durante el siglo pasado y la primera mitad del presente. De esta sección proviene la mayor parte de los antecedentes que aqui se exponen.
} 
de la vinculación fue reemplazado por conexiones transnacionales producto de los intereses económicos en Chile y del creciente peso estadounidense en el sistema internacional. No obstante, la sociedad chilena ha sido progresivamente influenciada por las políticas norteamericanas determinando la relación bilateral y su propio desarrollo interno, a pesar de que Chile no ha apoyado sus acciones hacia América Latina. De cualquier manera, tanto las clases dirigentes como los grupos sociales en general han discrepado con respecto a la percepción de los lazos mutuos y las políticas de la nación del norte. ${ }^{57}$

Las primeras desaveniencias datan de los inicios de Chile como país independiente. Si bien Joel Poinsett-el primer agente norteamericano recibido oficialmente- fue un decidido partidario de la independencia, se le habían dado instrucciones expresas para que no manifestara síntomas de reconocimiento a la nueva nación. ${ }^{58}$ Sin embargo, su presencia produjo roces con la aristocracia criolla, el clero y el pueblo en general, dada su cercanía al general José Miguel Carrera, su adhesión al protestantismo y su injerencia en la Constitución de 1812.59 También le acarreó dificultades con Gran Bretaña que protestó formalmente en contra de Estados Unidos por intervenir en asuntos que le eran ajenos, lo que reflejaba los inicios de la rivalidad entre estos dos países manifestada por el interés de penetrar en América del Sur. En todo caso, esta misión no tuvo consecuencias importantes. ${ }^{60}$

Al mismo tiempo, Estados Unidos se negó a prestar ayuda concreta en respuesta a las demandas de Jos latinoamericanos en favor de la independencia. A esta controversia se agregó la llegada de la misión encabezada por el diplomático Theodorick Bland en 1818, que también produjo reacciones encontradas debido a sus opiniones contrarias al movimiento independentista lo que trajo consigo la enemistad de O'Higgins. La situación se agravó con la negativa de Washington a reconocer el bloqueo a la costa peruana ordenado por el Almirante Cochrane al año siguiente, lo que provocó la

\footnotetext{
57 Ibid., pp. 11-14.

${ }^{8}$ Un hecho que simboliza la visión positiva que habia en Chile hacia Estados Unidos en ese momento sucedió el 4 de julio de 1812, cuando se celebró en Santiago oficialmente el aniversario de la independencia del país del norte, ocasión en que se exhibió la nueva bandera de Chile junto a la de esa nación. Serglo Villalobos et al, op. cit., pp. 534-536.

59 Mario Barros van Buren, op. cit., pp. 46-47.

${ }^{60}$ Cristián Guerrero Yoacham, "Chile y Estados Unidos: Relaciones y problemas, 1812-1916", en: Walter Sánchez G. y Teresa Pereira L., op. cit., p. 66.
} 
captura de los barcos norteamericanos que trataron de romperlo.

La tensión cedió cuando el Congreso de los Estados Unidos reconoció la independencia de Chile y en 1824 llegó al país Herman Allen como primer representante ante el nuevo gobierno.

Pero el ambiente que existía en esos momentos no era propicio. Paralelamente a estos hechos Estados Unidos había proclamado Ia Doctrina Monroe, cuyo objetivo era impedir la intervención de los países europeos en los asuntos hemisféricos bajo la garantía del gobierno norteamericano y que en Chile tuvo un impacto más bien negativo ${ }^{61}$.

A este respecto de sobra es conocida la reacción que tuvo Diego Portales ante las palabras del Presidente Monroe frente al Senado de su país en 1822 y que más tarde se plasmarían en dichos principios doctrinarios. Es así como prevenía del peligro que podía significar "salir de una dominación para entrar en otra" y la necesidad de "desconfiar de esos señores que muy bien aprueban la obra de nuestros campeones de liberación, sin habernos ayudado en nada". Portales pensaba que todo obedecía a una acción premeditadamente planificada y que implicaría "hacer la conquista de América, no por las armas, sino por la influencia en toda esfera. Esto sucederá tal vez no hoy; pero mañana sí. No conviene dejarse halagar por estos dulces que los niños suelen comer con gusto, sin cuidarse de un envenenamiento". 62

De esta manera, la falta de apoyo demostrada por Estados Unidos durante la independencia constituyó una primera fuente concreta para la hostilidad de Portales hacia esa nación y, luego, en los fundamentos declarados en esta doctrina percibió como pocos las ambiciones de Estados Unidos. ${ }^{63}$

Por su parte, Chile sólo envió un representante a Estados Unidos en 1827 , don Joaquín Campino, quien trató infructuosamente de lograr un acuerdo de amistad, navegación y comercio con Washington. Este fue otro ejemplo del distanciamiento entre ambos países, ya que las reclamaciones navales entorpecían el diálogo y el tratado sólo fue firmado más tarde gracias a las

\footnotetext{
${ }^{61}$ Esta doctrina no fue cumplida por diversos motivos: ni Estados Unidos ni las potencias europeas la respetaron debido a que el primero tuvo que ceder frente a Gran Bretaña y Francia; las jóvenes naciones no eran capaces de impedir los bloqueos y las invasiones a sus costas; Estados Unidos no ayudó a los ejércitos patriotas; los comerciantes norteamericanos continuaron vendiendo armas y barcos indiscriminadamente; etc. Mario Barros van Buren, op. cit., p. 80.

${ }^{62}$ Cristián Guerrero Yoacham, op. cit., p. 69.

63 Lawrence Littwin, op, cit., pp. 40-41.
} 
gestiones entre Andrés Bello y el Encargado de Negocios de Estados Unidos en Santiago, John Hamm. ${ }^{64}$

A raíz de este convenio, Estados Unidos pudo reanudar las reclamaciones surgidas durante la independencia y es así como buena parte de las relaciones entre ambas naciones hasta la década del sesenta estuvieron marcadas por los problemas y roces generados por estas demandas debido a que la política chilena fue rechazar los reclamos, especialmente las indemnizaciones. ${ }^{65}$

Por otra parte, diversas disputas originadas por el control del comercio en las costas del Pacífico Sur enfrentaron a ambos países. La guerra entre Chile y la Confederación Perú-Boliviana ejemplificó claramente esta situación, ya que el país del norte temía que un triunfo de Chile implicaría un desequilibrio de poder en la subregión y que el gobierno chileno impondría una política proteccionista que perjudicaría los intereses económicos de Estados Unidos. De ahí que aunque éste trató de evitar el conflicto manteniendo una posición neutral, su postura fue sólo retórica ya que en el fondo se mostró favorable hacia Perú y Bolivia. ${ }^{66}$

Hacia mediados del siglo XIX, el claro apoyo que Chile dio a México durante el enfrentamiento que mantuvo este país con Estados Unidos (1845-1848) aumentó las dificultades. Otro hecho que marcó la relación en forma negativa fue la reacción chilena ante el maltrato a ciudadanos chilenos en California durante la fiebre del oro. La situación se había vuelto tan tensa que, según informaba a su gobiemo el representante norteamericano en Chile, la prensalocal atacaba constantemente a su país y sus ciudadanos. Asimismo, muchas personalidades chilenas condenaban la política exterior norteamericana, enjuiciaban el materialismo individualista de Estados Unidos y favorecían la unidad hispanoamericana. ${ }^{67}$

\footnotetext{
${ }^{64}$ Este tratado fue muy importante para la diplomacia chilena porque fue la primera vez que se incorporó la "cláusula de la naciōn más favorecida" y, a través de él, Chile obtuvo concesiones que se no se habỉan dado a otras naciones del continente. Con respecto a la fecha de suscripción de este convenio, los autores investigados difieren en el año. Es así como Mario Barros sostiene que se suscribió en mayo de 1831, Cristiăn Guerrero en 1832 y, finalmente, Muñoz y Portales lo sitúan dos años más tarde. Algo similar ocurre con la fecha de reconocimiento de la independencia de Chile por parte de Estados Unidos. El primer autor lo fija en marzo de 1822, el segundo en enero de 1823 y los últimos en enero de 1832.

65 Se destacan las reclamaciones por los barcos capturados Macedonian y Warrior, por las cuales chile finalmente pagó lo que correspondia. Posteriormente, en 1848 , se produjo el problema del barco Gold Rush. Cristián Guerrero Yoacham, op. cit., pp. 70-71.

${ }^{66}$ En ese mismo período se produjo la partida del delegado norteamericano Seth Barton, luego de una disputa con el Arzobispo de Santiago, lo que motivó la solicitud del gobierno estadounidense de retirar al representante. Heraldo Muñoz y Carlos Portales, op. cit., pp. 21-22.

67 lbid., pp. 22 y 33.
} 
Las continuas anexiones territoriales de Estados Unidos producto de la guerra contra México, las actividades filibusteras de William Walker en Nicaragua, las pretensiones en Cuba, en las Islas Lobos cerca de la costa del Perú y las acciones de aventureros en Baja California, igualmente preocuparon a los chilenos. Esto impulsó la realización en Santiago en 1856 de una conferencia para establecer una unión con el fin de proteger a América Latina de la intervención de una gran potencia, a la cual sólo asistieron Perú y Ecuador. Si bien no tuvo éxito, de allí salió un tratado tripartito en el que cada miembro estaba obligado a prestar ayuda a los demás con el fin de rechazar a los "filibusteros" de sus costas, lo que mostró la aprehen-sión que algunas repúblicas sudamericanas tenían ante el expansionismo norteamericano. ${ }^{68}$

Asimismo, Chile se sintió preocupado cuando en 1854 Ecuador y Estados Unidos firmaron un convenio según el cual, a cambio de la concesión de guano de las Islas Galápagos, este último pagaría una suma de dinero y daría protección a sus costas e islas. Para el primero esta era una forma de frenar a sus vecinos peruanos y colombianos, pero Chile consideró el acuerdo como una amenaza a la paz y el equilibrio sudamericano, ya que Ecuador podía perder su independencia transformándose tarde o temprano en otra posesión norteamericana y los otros países estarían en peligro ante las pretensiones de la gran potencia. Por esa razón Chile envió una misión especial a Quito para evitar su ratificación o, si ya había ocurrido esto, ofrecer ayuda financiera para que Ecuador pudiera eludir su compromiso. Al mismo tiempo, solicitó la cooperación al resto de las naciones sudamericanas para frustrar "el establecimiento de un protectorado de Estados Unidos sobre Ecuador" e informó a varios países europeos previniéndolos de la actitud avasalladora asumida por Estados Unidos en el subcontinente. ${ }^{69}$ En todo caso dicho tratado no prosperó debido a que las exploraciones demostraron la inexistencia de los ambicionados yacimientos de guano y, por otra parte, Perú realizó diversas acciones para motivar su fracaso dado que no le convenía la idea de un protectorado norteamericano en Ecuador. ${ }^{70}$

Si bien la Guerra de Secesión en Estados Unidos provocó un acercamien- 
to dada la simpatía de los chilenos por los principios anti esclavistas que en ésta se esgrimían, la relación volvió a deteriorarse en 1865 debido a la neutralidad que sostuvo Estados Unidos durante la guerra de España contra Chile, Perú y Ecuador. Así, el comportamiento norteamericano demostraba la adhesión hacia la nación europea y comprobaba la inutilidad de la Doctrina Monroe. Chile expresó su disgusto frente este hecho ante lo cual el entonces Secretario de Estado norteamericano respondió que Estados Unidos no podía intervenir como aliado en cada una de las guerras que países amigos emprendieran. ${ }^{71}$

Como lo manifiestan los estudiosos de la Guerra del Pacífico de 1879, las rivalidades entre ambas naciones se profundizaron aún más durante este conflicto ya que la actitud y la política norteamericana fueron interpretadas como intervencionistas y favorables a Perú. Este comportamiento influyó en la imagen negativa que en Chile se tenía de Estados Unidos y aumentó la desconfianza que ya existía. De esta manera, algunas actuaciones norteamericanas fueron vistas claramente como reflejo de la posición anti chilena asumida. ${ }^{72}$

Por un lado, esta nación que sentía una profunda anglofobia, percibía a Chile como un simple peón de Gran Bretaña y pretendía impedir la intromisión europea. Por otro, los norteamericanos querían evitar a toda costa pérdidas territoriales de Perú en favor de Chile, lo que en su opinión restablecería el equilibrio estratégico en el Pacífico y no aceptaban la tesis chilena de que un acuerdo de paz necesariamente involucraba transferencia de territorio. La situación se resolvió por un acuerdo directo entre las partes -el Tratado de Ancón de 1883- y no como lo deseaba Estados Unidos, mediante una negociación que pudiera manejar e intervenir de acuerdo a sus propios intereses. No obstante el país del norte interferiría nuevamente más tarde debido a que el acuerdo pospuso el futuro de las provincias de Tacna y Arica. ${ }^{73}$

Posteriormente, en 1891, se produjeron otras situaciones que incidieron

${ }^{n}$ Cristián Guerrero Yoacham, op. cit., p. 74 .

72 Guerrero describe diversas acciones de los representantes norteamericanos en Lima, Santiago y La Paz para conseguir que Estados Unidos jugara un papel de mediador, algunas de las cuales fueron vistas no sólo contrarias e inaceptables a los intereses chilenos sino que obedecían a asuntos estrictamente personales. lbid., pp. 74-75.

73 Heraldo Muñoz y Carlos Portales, op. cit., pp. 23-26. 
negativamente en las relaciones bilaterales. Un ejemplo fue la actuación de Estados Unidos en la guerra civil, ya que respaldó decididamente al Presidente Balmaceda, enfrentando a la Junta de Iquique y al bando congresista que resultarían vencedores. ${ }^{74}$ Por su parte, los países europeos (Francia, Alemania y Gran Bretaña) apoyaron a los rebeldes principalmente debido a que tenían intereses económicos que resguardar. ${ }^{75}$

De igual forma, el "incidente del Itata"76 causó un profundo malestar en la opinión pública general y una evidente actitud anti norteamericana en las fuerzas victoriosas. Otros acontecimientos y "el asunto del Baltimore" ese mismo año acrecentaron el distanciamiento. ${ }^{77}$ Este último provocó una situación tan tensa que estuvo muy cerca de llevar a ambos países a un conflicto mayor. Los chilenos miraron a Europa buscando ayuda, pero a pesar de que estos países simpatizaban con su causa, ninguno estuvo dispuesto a socorrerlo. ${ }^{78}$

Según Mario Barros, la cuestión del Baltimore también tuvo como consecuencia que la ciudadanía chilena en general se pronunciara por España en su guerra con Estados Unidos en 1898. Pero aún más importante fue que contribuyó a que Chile sentara las bases de su política exterior sobre los cuatro fundamentos que nombramos anteriormente. ${ }^{79}$

\footnotetext{
${ }^{74}$ Segün Guerrero, el representante de Estados Unidos en Chile Patrick Egan, quien era irlandés por nacimiento pero había tomado la nacionalidad norteamericana, era manifiestamente antibritănico lo que justificó su respaldo decidido a Balmaceda como contrapartida del apoyo otorgado por los ingleses a la Junta de lqquique y al grupo contrario a la causa presidencial. Cristián Guerrero Yoacham, op. cit., p. 78.

75 Emilio Meneses C., op.cit., p. 16.

${ }^{76}$ Este barco había ido a recoger a la bahía de San Diego, California, un cargamento de armas y municiones que habían sido compradas por las fuerzas congresistas a través de sus agentes en Estados Unidos. Pero, segứn el Departamento de Estado, la partida del barco de la bahía había violado las leyes de neutralidad norteamericana por lo que se ordenó su apresamiento. Este hecho fue desmentido dos años más tarde por la Corte Suprema de Estados Unidos, pudiendo regresar con su cargamento a Chile. Cristiăn Guerrero Yoacham, op. cit., p. 78. 7 La imagen negativa aumentó con la acusaciôn de espionaje al almirante estadounidense George Brown al têrmino de la revolución y por el otorgamiento de asilo diplomático a miembros del vencido grupo presidencial. Pero más grave aún fue lo sucedido a raíz del asesinato de dos marinos del buque estadounidense Baltimore durante una riña con civiles chilenos y que provocó que Estados Unidos pidiera excusas oficiales y pago de indemnizaciones al gobierno chileno. Desde el punto de vista de sus dirigentes políticos, la situación ameritaba el rompimiento de relaciones diplomáticas e incluso el uso de la fuerza en caso de que Chile no respondiera a sus demandas. Finalmente el problema se solucionó con la decisiôn del gobierno chileno de indemnizar a las familias de las víctimas, pero quedó la impresión de que un simple hecho policial había sido transformado por Estados Unidos en un asunto internacional. La pugna se manifestó tambiên en 1885 con el envio de parte de Chile de un crucero para defender los derechos de Colombia en el istmo de Panamá, con los roces entre las marinas de ambos países durante la guerra entre Estados Unidos y España en 1898, y con la resistencia chilena a los intentos norteamericanos de ocupar las islas Galápagos. Heraldo Muñoz y Carlos Portales, op. cit., pp. 26-28.
}

${ }^{78}$ Emilio Meneses C., op.cit., p. 17.

79 Mario Barros van Buren, op, cit., p. 532. 
Al finalizar el siglo XIX ocurrieron otros dos hechos que enturbiaron las relaciones: los casos del contrato Lord y de la reclamación Alsop. ${ }^{80}$

En opinión de Muñoz y Portales, "las sucesivas crisis en las relaciones bilaterales, particularmente con posterioridad a la Guerra del Pacífico, indicaban la existencia de una rivalidad entre dos potencias emergentes, una que se proyectaba en el ámbito mundial y la otra en el regional. Durante la segunda mitad del siglo XIX y, especialmente luego de su triunfo en la Guerra del Pacífico, Chile había surgido como una verdadera potencia en América del Sur y su prestigio político internacional era ampliamente reconocido", lo que encontró una abierta oposición en el gobierno y la opinión pública de Norteamérica. ${ }^{81}$

Aunque hoy nos resulta sorprendente y hasta absurda esta rivalidad teniendo en cuenta el peso y las dimensiones actuales de cada uno, en aquella época no lo fue. Por el contrario, descontando a Estados Unidos, Chile era el único país americano políticamente organizado y estable; aunque en forma moderada había progresado económicamente y tenía grandes perspectivas gracias a la explotación de productos como el salitre y probablemente el guano; había demostrado su fuerza militar en la Guerra del Pacífico y contaba con un buen ejército y una escuadra incluso más poderosa que la norteamericana.

Así, ambos países se enfrascaron en una competencia en la que cada uno exhibía sus recursos y capacidades. Por un lado, a fines del siglo XIX Chile consideraba su superioridad bélica como una muestra clara a cualquier coalición que intentara oponérsele, renunciando a su tradicional política del equilibrio de poder en Sudamérica y luchando por lograr una posición preponderante en el continente. Por el otro, Estados Unidos se visualizaba como una potencia global de naturaleza económica, política y estratégica que pretendía la supremacía en el hemisferio occidental.

Esta competencia, que según estos mismos autores quedó en la memoria histórica de las relaciones bilaterales, explica en parte el distanciamiento

\footnotetext{
so El primero tuvo que ver con un contrato para construir un ferrocarril entre Chile y una compañía norteamericana que el entonces Presidente Balmaceda anuló alegando incumplimiento de la contraparte. La controversia finalizó con un pago efectuado por Chile a los perjudicados. El segundo estuvo relacionado por protestas por daños causadas durante la Guerra del Pacífico y tamblén llegó a amenazar las relaciones entre ambos países, resolviêndose en 1911 mediante arbitraje británico. Heraldo Muñoz y Carlos Portales, op. cit., pp. 26-28.

81 lbid., p. 29.
} 
entre ambas naciones y durante el siglo pasado se convirtió en uno de los pilares de una "cultura anti norteamericana" que atravesó los diversos grupos sociales y políticos chilenos. Sin embargo, cabe hacer notar como se dijo más adelante, que las percepciones entre los distintos sectores no eran homogéneas.

Por último, como lo manifiesta un autor, el anti norteamericanismo orientó de algún modo al país hacia Europa, región que culturalmente sentía más cercana y las ideas que se desarrollaron en países como Francia, España e Italia, tuvieron un gran impacto en la posición de algunos intelectuales tanto liberales como conservadores. Especialmente importante fue la influencia de Gran Bretaña, tanto en el plano intelectual como en el económico y político. ${ }^{82}$

\section{La vinculación con la región del Pacífico}

Según se mencionó en la primera parte de este trabajo, las rasgos geográficos de Chile condicionaron de alguna manera su relación con el exterior. Uno de los más determinantes fue su carácter insular, en el sentido de que los límites naturales lo aislaron del resto del mundo. Más aun, el hecho de que una de estas fronteras estuviera conformada por una extensa costa forzó a que desde un comienzo se orientara hacia el mar.

Chile ha tenido un gran interés en la región del Pacífico y se puede afirmar que constituye uno de los elementos que ha estado presente a través de su quehacer internacional. Ën esta sección examinaremos algunos de los primeros indicios de la vinculación del país con esta área, sin aludir a los primeros antecedentes que se pueden encontrar también en el período colonial.

La permanencia de esta relación en ningún caso quiere decir que fuera especialmente intensa y regular, involucrara un volumen de comercio elevado o reflejara una acción planificada. Pero sí significó una constancia a través del tiempo que es importante señalar. Las vinculaciones se desarrollaron principalmente en el plano comercial, impulsadas mayormente por la iniciativa privada, y eventualmente obedecieron a una política claramente

\footnotetext{
${ }_{82}$ Lawrence Littwin, op. cit., pp. 48-56. Cita varios ejemplos del peso que tuvo Gran Bretaña en Chile, especialmente a partir de 1831 , año en que reconoció su independencia.
} 
diseñada con ese fin. Además hubo contactos oficiales a través del establecimiento de consulados y oficinas comerciales, así como viajes de la Armada. ${ }^{83}$

El pensamiento internacional de Diego Portales mostró ya claramente que "la gran vocación internacional de Chile es y debe ser el mar" y que como país marino "debe orientar toda su política exterior a ser un poder comercial en el Océano Pacífico", para lo cual era indispensable contar con una gran marina mercante y una poderosa marina de guerra. ${ }^{84}$ Tomando en cuenta el espíritu nacionalista que lo embargaba, Portales consideraba que para que Chile llegara a ser un país grande y fuerte debía distanciarse de los asuntos americanos y alcanzar una preponderancia naval en el Pacífico. ${ }^{85}$

Como ministro y hombre de negocios asentado en Valparaíso, le asignó mucha importancia a este puerto confirmando claramente su vocación. Así, en el período del Presidente Prieto, se tomó una serie de medidas con el fin de hacer de éste el centro del comercio de la costa occidental americana aprovechando su privilegiada ubicación. ${ }^{86}$

Por otro lado, los intereses vitales que Chile tenía en el Pacífico determinaron en parte su involucramiento en el conflicto con la Confederación PerúBoliviana. Entre 1836 y 1839, el país se enfrentó a Perú y Bolivia cuando vio comprometido el equilibrio continental, lo que hacía peligrar no sólo su propia estabilidad interna sino también sus ambiciones comerciales y su posición en el mar. Después del triunfo se convirtió en el regulador del equilibrio de poder a lo largo de toda la costa llegando a ejercer la hegemonía en el Pacífico.

También la rivalidad existente entre Chile y Estados Unidos fue un reflejo de la disputa por el dominio del comercio en las costas del Pacífico.

\footnotetext{
${ }^{83}$ Gloria Echeverria, Francisco Orrego y Luz O'Shea, "Los intereses de Chile en el Pacífico", Revista de Educación, №96, Santiago 1982, p. 12.

${ }^{84}$ Mario Barros van Buren, op. cit., p. 108.

8s Walter Sánchez, op. cit., p. 384 .

${ }^{86}$ Entre dichas acciones, se comisionó al nałuralista francés Claudio Gay para que realizara un inventario de las riquezas del país cuyo objetivo era promover la industria nacional y atraer a los inversionistas extranjeros; se ordenó mejorar, reparar y agrandar las facilidades portuarias que alli se encontraban; se dictó una ley para crear almacenes en las cuales los productos en tránsito no pagaran impuestos aduaneros y de esta forma captar manufacturas europeas y asiăticas e intercambiarlas con productos de México y Perú. Para fomentar el uso interno del puerto, se planificicó una política naviera para organizar una marina mercante nacional y un sistema de navegación a vapor (mediante una concesión otorgada al norteamericano William Wheelwright por 10 años) y se establecieron tarifas preferenciales para las mercancías transportadas por barcos de propiedad de chilenos o construidos en el país. Robert Burr, op. cit., pp. 16-17.
} 
Esto quedó demostrado tanto en el enfrentamiento con la Confederación Perú-Boliviana como en la Guerra del Pacífico ya que, de acuerdo a lo que vimos anteriormente, en ambos sucesos estaba en juego la supremacía en este océano. En el primero, a pesar de que asumieron la neutralidad, los norteamericanos mantuvieron una posición más bien proclive a las naciones enemigas de Chile. De la misma manera, durante la Guerra del Pacífico cuarenta años después, se mostraron partidarios de Perú y fueron acusados de intervencionistas. La pugna con Chile persistía debido a que éste emergía como una verdadera potencia sudamericana en esta área oceánica.

La aparición de nuevos mercados en el Pacífico permitió iniciar un intercambio comercial que contribuyó por algunos años favorablemente a la economía nacional. Este comercio fue irregular y estuvo condicionado por las coyunturas internas del momento, las posibilidades que se ofrecían en el ámbito internacional y por la complementariedad o la competencia entre las economías. De cualquier modo, los volúmenes fueron muy bajos comparados, por ejemplo, con los que se llevaron a cabo con Europa. ${ }^{87}$

Si bien hacia mediados del siglo XIX las exportaciones de trigo hacia Perú se habían recuperado considerablemente, aún eran inferiores a las de la etapa colonial. Pero, con la apertura de los mercados de California y Australia, esta situación cambió positivamente para Chile.

Aunque fue por un corto tiempo -entre 1849 y 1854 - el hallazgo de oro en California permitió el aumento espectacular de las ventas de trigo, harina y otros productos chilenos ${ }^{88}$, Io que continuó hasta que la región pudo auto abastecerse. Entonces el intercambio se revirtió y la harina californiana comenzó a venderse en Valparaíso a la mitad de precio de la nacional. Se comprobó así que la industria en este rubro no podía expandirse al ritmo adecuado y que Chile era incapaz de competir contra fletes y costos menores. ${ }^{89}$

En todo caso, después del auge de California, las exportaciones de estos bienes hacia el Pacífico prosiguieron, esta vez gracias al oro descubierto en Australia en 1851. A pesar de que se creyó que este mercado prometía más

${ }^{87}$ Gloria Echevería, Francisco Orrego y Luz O'Shea, op. cit., pp. 12:13.

${ }^{88}$ Según Mario Barros, hubo tambiên un fuerte fomento del transporte que se notó en la gran cantidad de naves que cubrian esta ruta ya que era mucho más barato llevar las mercancías desde Valparaíso que comprar en el atlántico oriental pasando por Panamá, el Estrecho de Magallanes o atravesando el oeste norteamericano. Mario Barros van Buren, op. cit., p. 212.

89 Sergio Villalobos et al, op. cit., pp. 481-484. 
que el anterior, las enormes distancias hicieron que Australia lograra ser auto suficiente y Chile perdió sus posibilidades. Sin embargo, como lo expresa Barros, "había renacido la idea de Portales de afincar la presencia chilena en el Pacífico".90

De esta manera, debido a que en 1849 los norteamericanos habían tomado posesión de las islas de Juan Fernández desconociendo que pertenecían a Chile, el gobierno ordenó el ocupamiento del archipiélago y dos años más tarde lo designó sub delegación de Valparaíso. Se inició entonces una nueva etapa de expansión hacia el Pacífico, produciéndose un incipiente comercio con Ias islas Hawai, Tahiti, Tasmania y Nueva Zelandia. Un síntoma de lo anterior fue el aumento en la fabricación de naves y la circulación de moneda chilena en estas lejanas tierras.

La destrucción de la marina mercante debido a la guerra con España, la apertura de mercados más fáciles a corto plazo y el conflicto con Perú y Bolivia, redujeron después esta expansión. ${ }^{91}$ Como consecuencia, Chile perdió el papel protagónico y se transformó en el principal intermediario latinoamericano del comercio en la región, realizando un no despreciable tráfico de reexportación de mercaderías europeas hacia el Pacífico e internando bienes asiáticos en naves de terceros países. ${ }^{92}$

Posteriormente, durante el gobierno de Balmaceda (1886-1891), el fomento de la expansión hacia el Pacífico volvió a ocupar un lugar destacado dentro de las actividades internacionales chilenas. Si bien como ya se señaló la idea venía del período de Prieto y Portales, una acción de este tipo no era pertinente mientras Chile y Perú pugnaban por esta supremacía. Sin embargo, la apertura de los nuevos mercados de California y Australia (a pesar de su precariedad en el tiempo) y la visión de algunos hombres de la época, contribuyeron posteriormente a llevar a cabo una política planificada.

Chile había quedado como amo absoluto del Pacífico luego haber salido vencedor en el conflicto de 1879 , poseía la marina de guerra más poderosa de Sudamérica y, gracias a la riqueza proporcionada por el salitre, había logrado financiar una excelente flota mercante. Estos factores hicieron que el Presidente Balmaceda ordenara tomar posesión de la Isla de Pascua en 1888.

\footnotetext{
90 Mario Barros van Buren, op. cit., p. 213.

91 lbid., pp. 213-214.

92 Gloria Echeverria, Francisco Orrego y Luz O'Shea, op. cit., pp. 13*14.
} 
La misión estuvo a cargo de la marina de guerra y la ocupación se realizó mediante la compra de los títulos de propiedad a los jefes indígenas. Se construyó una base inicial, pero la guerra civil de 1891 frenó los planes. Cuando en 1892 los franceses quisieron adueñarse de la isla, se encontraron con que Chile ya lo había hecho unos años antes. La apropiación efectiva por parte de Chile de este territorio de la Polinesia contribuyó decididamente a consolidar su presencia en el Pacífico. ${ }^{93}$

En las dos últimas décadas del siglo pasado el comercio a través del Pacífico experimentó un repunte y a los mercados tradicionales se agregaron otros interesados en comprar productos chilenos, particularmente salitre.

En el intertanto y como consecuencia del permanente intercambio comercial con apartadas regiones de la cuenca, a partir de 1845 el gobierno de Chile designó representantes oficiales en diferentes lugares. Se establecieron consulados en Cantón, Auckland, Hong-Kong, Manila, Papeete, Melbourne, Sidney, Honolulu, Bombay, Calcuta y Brunei, a lo que cabe agregar una Legación en Tokio y una oficina comercial en China. También la Armada a partir de 1886 realizó frecuentes viajes por la región. ${ }^{94}$

\section{Conclusiones}

La actual política exterior de Chile está sometida a un complejo proceso de cambios cuya fuente se encuentra en factores provenientes tanto del plano interno como del externo. Pero, a diferencia de lo que ocurrió tradicionalmente en que la política exterior estuvo condicionada por variables domésticas, se puede sostener con seguridad que actualmente son las transformaciones que ocurren en el escenario internacional las que tienen un peso mayor.

Una aproximación histórica a las relaciones internacionales chilenas constituye un valioso aporte para explicar el actual posicionamiento. Hacer una referencia al pasado se justifica porque allí se encuentra gran parte de las pautas que han guiado antes y hoy a los formuladores de la política exterior.

\footnotetext{
93 Mario Barros van Buren, op. cit., pp. 497-498.

94 Gloria Echeverria, Francisco Orrego y Luz O'Shea, op. cit., p. 14.
} 
Las características geográficas, la conformación de la población y de la sociedad, el desarrollo político y económico, las formas culturales y valóricas, han condicionado de alguna manera el comportamiento internacional de Chile.

Podemos afirmar que el origen de algunos de los principios que rigen las relaciones internacionales contemporáneas se encuentra en la etapa inicial de la formación de Chile como Estado-nación y en sus primeras actuaciones en el plano internacional. Quizás las figuras de Diego Portales y Andrés Bello, constituyen las más emblemáticas en este sentido.

Todos los patrones que identificamos -la tradición legalista, la doctrina de equilibrio de poder, la relación ambigua con Estados Unidos y la vinculación con el Pacífico- estuvieron presentes desde que el país comienza a autogobernarse y a relacionarse con el exterior. $Y$ todos ellos, también, permanecieron a lo largo del siglo XIX, aunque en forma intermitente; dependiendo de las circunstancias afloraron o quedaron latentes.

Teniendo en cuenta la situación actual de las relaciones internacionales y los elementos prioritarios que las rigen -que no necesariamente son los mismos que se dieron históricamente- podemos afirmar que el apego al legalismo permanece inalterable como un principio muy arraigado en la cultura política nacional. Con respecto al equilibrio entre los países, considerando la globalización y los acuerdos regionales logrados con los vecinos, Chile aspira a una relación equitativa y complementaria más que de competencia con los países de su entorno. Los problemas vecinales que en el pasado determinaron la forma de relacionamiento, y que en muchos casos aún persisten, son superados por otros intereses que se consideran más valiosos y que se traducen, por ejemplo, en nuevas tendencias hacia formas de regionalismo más abiertas. Por otra parte, la relación con Estados Unidos, que constituye un área de gran importancia para la política exterior chilena, continúa pasando por momentos de cercanía y alejamiento. Por último, la vinculación con la Cuenca del Pacífico a pesar de que no ha estado exenta de dificultades, ha adquirido gran relevancia básicamente por razones comerciales, corroborando un patrón establecido desde siempre.

En el siglo pasado las relaciones internacionales estuvieron subordinadas a la política interna, sin embargo hoy en día la vinculación con el exterior es preferente. El proceso de internacionalización en el que es país está inmerso y el ritmo y la intensidad de las transformaciones que ocurren en el 
ámbito regional así lo exigen.

Ante esta innegable realidad, es necesario evaluar la adaptación de los instrumentos actuales de la política exterior para encarar los desafíos a que se ve enfrentado el país. Esto es más importante aún porque estos retos están enmarcados en una forma de vinculación creciente y cualitativamente distinta de Chile con el mundo.

La forma en que Chile se ha posicionado frente a los procesos de globalización y regionalización que se están produciendo a escala mundial y regional, difiere de las tendencias tradicionales de la política exterior chilena y de las políticas adoptadas por nuestros vecinos más inmediatos. La búsqueda de un regionalismo abierto; la política vecinal; el regionalismo renovado de la política latinoamericana y la participación en mecanismos de concertación regional; las vinculaciones con América del Norte, Europa, Asia-Pacífico; la activa participación en al ámbito multilateral; constituyen los principales desafíos y las tendencias emergentes que se proyectan al presente. 
Bibliografía:

Pilar Alamos Varas

Algunas fuentes históricas de la política exterior de Chile.

Barros van Buren, Mario, Historia Diplomática de Chile. Santiago: Editorial Andrés Bello, 1990.

Burr, Robert, By Reason or Force. Chile and the Balancing of Power in South America, 1830-1905. Berkeley and Los Angeles: University of California Press, 1967.

Davis, Harold Eugene and Wilson, Larman C. (eds), Latin American Foreign Policies. Baltimore and London: The Johns Hopkins University Press, 1975.

Echeverría, Gloria; Orrego, Francisco y O'Shea, Luz, "Los intereses de Chile en el Pacífico", Revista de Educación, $N^{\circ} 96$, Santiago, 1982.

González E., Javier, "El aporte de Portales a la formación del Estado nacional como base de una política exterior", en: Sánchez G., Walter y Pereira L., Teresa, 150 años de política exterior chilena. Santiago: Editorial Universitaria, 1977, pp. 33-43.

Guerrero Yoacham, Cristián, "Chile y" Estados Unidos: Relaciones y problemas, 1812-1916", en: Sánchez G., Walter y Pereira L., Teresa, 150 años de política exterior chilena. Santiago: Editorial Universitaria, 1977, pp. 65-82.

Littwin, Lawrence, An integrated view of Chilean Foreign Policy. Ann Arbor, Michigan: University Microfilms, Inc., 1987.

Meneses C., Emilio, "Coping with Decline: Chilean Foreign Policy during the Twentieth Century, 1902-1972". Tesis de Doctorado, Balliol College, Universidad de Oxford, 1987.
Muñoz, Heraldo y Portales, Carlos, Una amistad esquiva. Las relaciones de Estados Unidos y Chile. Santiago: Pehuén, 1987.

Sánchez, Walter, "Las tendencias sobresalientes de la política exterior chilena".

Sánchez G., Walter y Pereira L., Teresa, 150 años de política exterior chilena.

Santiago: Editorial universitaria, 1977, pp. 374-415.

Villalobos R. Sergio, "La situación internacional y la independencia de Chile".

Sánchez, G., Walter y' Pereira L., Teresa, 150 años de política exterior chilena.

Santiago: Editorial universitaria, 1977.

Villalobos R., Sergio; Silva G., Osvaldo; Silva V., Fernando; Estellé M., Patricio, Historia de Chile.

Santiago: Editorial Universitaria, 1974.

Wilhelmy, Manfred, "Hacia un análisis de la politica exterior chilena contemporánea", Revista Estudios Internacionales, $N^{\circ} 48$, Año XII, octubre-diciembre 1979, pp. 440-471. 